\title{
Are we making a difference in primary care for adults with intellectual and developmental disabilities?
}

\author{
Hélène Ouellette-Kuntz, ${ }^{1}$ Glenys Smith, ${ }^{2}$ Casey Fulford, ${ }^{3}$ and Virginie Cobigo ${ }^{3}$
}

Suggested citation

Ouellette-Kuntz H, Smith G, Fulford C, Cobigo V. Are we making a difference in primary care for adults with intellectual and developmental disabilities? Rev Panam Salud Publica. 2018;42:e154. https:/ / doi. org/10.26633/RPSP.2018.154

\begin{abstract}
Objectives. To examine the impact of the dissemination of guidelines to physicians and of a population-level health communication intervention on the percentage of adults with intellectual and developmental disabilities (IDD) receiving preventive care through primary care.

Methods. Noninstitutionalized adults with IDD in the province of Ontario, Canada, aged 40 to 64 years were matched to Ontarians without such disabilities each fiscal year (FY) from 2003 to 2016. Health administrative data were used to create a composite measure of receipt of recommended preventive primary care. Age-adjusted rates were used to assess trends, and average two-year rate ratios (RRs) and confidence intervals (CIs) were used to evaluate the effectiveness of the interventions.

Results. The number of adults with IDD identified ranged from 20030 in FY 2003 to 28080 in FY 2016. The percentage of adults with IDD receiving recommended preventive primary care ranged from $43.4 \%$ in 2003 to $55.7 \%$ in 2015. Men with IDD had a 53.7\% increase across the 13 years, while women with IDD only had a $30.9 \%$ increase. When evaluating the impact of the interventions, men with IDD were 4\% more likely (RR: 1.04; 95\% CI: 1.02-1.05) to receive recommended primary care in FY 2015 and FY 2016 as compared to FY 2009 and FY 2010; in contrast, women with IDD were 5\% less likely (RR: 0.95; 95\% CI: 0.93-0.98). A comparable drop was observed among women without IDD.

Conclusions. Nearly $45 \%$ of adults with IDD in Ontario still do not receive recommended preventive care through primary care. Long-term impacts of the interventions introduced in the province may still occur over time, so ongoing monitoring is warranted. Special attention should be given to the preventive care needs of women with IDD.
\end{abstract}

Keywords Preventive health services; intellectual disabilities; primary health care; Canada.

In 2003, an International Think Tank on Reducing Health Disparities was held in Ottawa, Canada; it included

\footnotetext{
Department of Public Health Sciences, Queen's University, Kingston, Ontario, Canada. Send correspondence to Dr. Hélène Ouellette-Kuntz, at helene.kuntz@queensu.ca.

2 Institute for Clinical Evaluative Sciences, Ottawa, Ontario, Canada.

3 School of Psychology, University of Ottawa,
} Ottawa, Ontario, Canada. representatives from Australia, Canada, Mexico, New Zealand, and the United States of America. The participants at that event identified individuals with disabilities (and intellectual and developmental disabilities (IDD) specifically) as one of 11 vulnerable populations with regards to being "more likely to become ill and less likely to receive appropriate

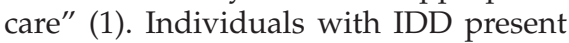

with cognitive deficits associated with limitations in activities of daily living that begin in the developmental period, typically before the age of 18 years. As a group, they are at greater risk for health problems and for using resource-intensive health care services. However, because of their disabilities, they have greater difficulty negotiating their way through health services (2), 
which are often delivered through a fragmented system.

Access to primary health care for this marginalized IDD population is of strong relevance to the Declaration of Alma-Ata (1979), which highlighted the need to address health and social inequalities and to promote social justice among citizens. Preventive health services are a key aspect of primary health care (3), yet most individuals with IDD are missing out on these opportunities for health promotion and disease detection, which have the potential to greatly reduce health care disparities among individuals with IDD and those without. There is recognition of the need for health promotion for people with disabilities in the Americas (4, 5). In the United States, research focusing on preventive health for individuals with IDD across the lifespan is being conducted (6). However, in Latin American countries, explicit strategies are lacking to address the specific health-related needs of individuals with IDD, including for primary care (7).

The periodic health examination provides an opportunity for primary care providers to ensure preventive care and undertake earlier disease detection. It is the time when health issues that are not addressed during other appointments can be discussed. The evidence specific to adults with IDD suggests that without a dedicated approach to health assessment, inadequate care will result (8). A 2006 Welsh study revealed the ability of such a health assessment to identify previously undiagnosed health problems among adults with IDD (9). Subsequently, a cluster randomized trial in Australia demonstrated that structured comprehensive health assessments (which included a review of patient medical history, focused physical examination, and development of a health action plan) for adults with IDD led to the early identification of health issues and the prevention of more complex difficulties (10).

In light of the international literature in support of the periodic health examination for adults with IDD, in 2006, Australia and Wales instituted specific funding to physicians as an incentive to perform annual health assessments for this patient group $(11,12)$. When combined with notifications of the importance of the examination being sent to adults with IDD and their caregivers, this incentive resulted in the uptake of the annual health assessment in this population increasing from $31 \%$ in $2006 / 2007$ to $41 \%$ in $2008 / 2009$ (12). The practice incentive was extended across the United Kingdom in 2009 (13). A similar increase in the uptake of health checks among adults with IDD was then seen in England, from $30.5 \%$ in 2010 to $41.7 \%$ in 2011 (14). There is a need to understand diverse strategies to improve the uptake of preventive care in different jurisdictional contexts.

\section{Context for the study}

Despite Canada's universal access to health care, few adults with or without IDD have a periodic health examination. Although there continues to be debate in Canada and elsewhere about the utility of the periodic health examination for all patients $(15,16)$, in Ontario (which is Canada's most populous province), the rate of uptake from 1 April 2009 to 31 March 2011 (fiscal year (FY) 2009 and FY 2010) was $22.0 \%$ for adults with IDD, as compared to $26.4 \%$ in the general population (17). Among the oldest group studied (55 to 64 years old), the disparity was greatest, with only $24.2 \%$ of those with IDD having had a periodic health exam, compared to $31.0 \%$ of those without IDD (18). Research in Ontario has also shown that women with IDD are significantly less likely to undergo recommended cervical and breast cancer screening than are women without IDD (19). This underscores the importance of promoting preventive care, including the periodic health examination, in the IDD population.

Canadian provinces have not created financial incentives targeting the periodic health examination for adults with IDD. However, practice guidelines that include the recommendation to perform annual health assessments for these patients have been developed and disseminated to all members of the College of Family Physicians of Canada (first in 2006 (20), and then in 2011, with a package of clinical tools (21)). In 2011, the Ontario government ministry responsible for policy in the area of IDD created 10 new positions to facilitate access to appropriate health care for adults with IDD. A key function of these health care facilitators has been to prepare and support their respective communities (primary care providers and IDD service agencies) to increase the adoption of the Canadian guidelines for the primary care of adults with IDD.
While primary care providers have received extensive education and outreach, our health care system requires self-referral for health assessments. Thus, engaging patients in the change process is also important. Despite the evidence that patient and caregiver empowerment approaches can increase preventive care in adults with $\operatorname{IDD}(10,22)$, these groups were only targeted in Ontario in 2014 through a population-level health communication intervention to empower adults with IDD to access recommended preventive care. In October 2014, a large segment of the population of adults with IDD (of which $56.4 \%$ were 40 years and over) was sent a letter about the initiative, a document with images explaining the importance of the annual health exam and how to book an appointment with one's physician for the exam, an information sheet about the project that could be given to their physician, and an invitation to contact researchers to be included in a follow-up telephone survey (23). While the envelope was addressed to the adult with IDD, where the individual did not have the ability to read, it was to be opened, read, and explained by a caregiver.

The objective of this study was to examine the impact of the efforts described above to improve the provision of preventive care to adults with IDD 40 to 64 years of age through primary care in Ontario, Canada. The efforts include the 2006 publication of consensus guidelines, the 2011 publication of revised guidelines, tool dissemination and introduction of health care facilitators, and the 2014 health communication intervention targeting adults with IDD in Ontario.

\section{MATERIALS AND METHODS}

We used a population-based longitudinal ecological design and routinely collected health administrative data. The study relied on a previously identified cohort of adults with IDD who were 18 to 64 years of age and living in Ontario in FY 2009 (24). For each year between FY 2003 and FY 2016, subgroups of noninstitutionalized individuals who were between 40 and 64 years old and living in the province were identified. The study was restricted to noninstitutionalized persons 40 to 64 years old since the preventive care measures of interest target this group. A comparison group of the remaining Ontario population was used 
to control for any secular trend. Initially, the comparison group was matched on sex in order to decrease the potential number of matches, and then matched on propensity score. The propensity score was calculated using age, sex, morbidity (number of Aggregated Diagnosis Groups (ADGs) from the Johns Hopkins ACG System Version 10), neighborhood income quintile, and rurality (from the 2008 Rurality Index of Ontario (RIO) (25)). A new propensity score-matched comparison group was created for each fiscal year (1 April to 31 March) to ensure the continued similarity of the groups over time. A one-to-one matching ratio, with a 0.2 caliper, was used.

Seven data sets held at the Institute for Clinical Evaluative Sciences (ICES) were used: 1) Ontario Diabetes Database (ODD); 2) Ontario Cancer Registry (OCR); 3) Ontario Health Insurance Plan (OHIP); 4) Discharge Abstract Database (DAD); 5) Same Day Surgery (SDS); 6) National Ambulatory Care Reporting System (NACRS); and 7) Registered Persons Database (RPDB) (for details about each of the data sets, see: https://datadictionary.ices.on.ca / Applications/DataDictionary/Default. aspx). The ICES Data Repository consists of individual-level health service records for much of Ontario's publicly funded system. All data sets held at ICES are anonymized and linkable through unique encoded identifiers. All analyses were conducted at ICES using SAS version 9.4 software (SAS Institute, Cary, North Carolina, United States).

A composite indicator of preventive care provision through primary care was used to measure the impact of the efforts to improve primary care provision. The composite indicator consisted of either a billing code indicative of a periodic health examination (PHE) or a value of 0.6 or greater on the Primary Care Quality Score (PCQS). The use of a composite indicator was deemed desirable due to anomalous physician billing practices and the lack of access to data related to screening tests completed in hospital or private lab settings. Previous work has demonstrated that the composite indicator identifies up $5 \%$ more adults with IDD over the age of 40 as having received recommended preventive care, as compared to using either a value of 0.6 or greater on the PCQS or PHE billing codes alone (26). As such, combining the two indicators reduces the risk of underestimating the outcome.

\section{Periodic health exam}

The periodic health exam was defined using Ontario Health Insurance Plan (OHIP) fee code A003 with diagnostic code 917 (apparently healthy adults) or 319 (adults with IDD). Starting 1 January 2013, the fee code for the health exam for apparently healthy adults was changed to K131. If an individual received either A003 with diagnostic code 917 or 319 or fee code K131 between 1 April and 31 March of the given year (the fiscal year), they were considered to have had a health exam.

\section{Primary Care Quality Score}

The Primary Care Quality Score (PCQS) was first presented by Dahrouge and colleagues at the 2015 North American Primary Care Research Group conference and later revised as Preventive
Care and Chronic Disease Management Performance Indicators (27). To calculate the PCQS for an individual, various administrative health data sets held at ICES were used to code all eligible preventive care measures listed in Table 1 as either up to date or not. For example, a 50-yearold male would be considered up to date with lipid screening if he had had a lipid test that year or within the previous five years. He would not be considered up to date with his glucose screening if it had been four years since his last glucose test. The PCQS was categorized as high or low; a high PCQS was a score $\geq 0.6$. In order to achieve a high PCQS, an individual would have had to have a minimum of two of their eligible preventive care measures up to date, including at least one cancer screening or both of the applicable blood tests (lipid and glucose for nondiabetics; lipid and hemoglobin A1c for diabetics) (28).

TABLE 1. Seven guideline-recommended preventive care measures included in the calculation of the Primary Care Quality Score, according to sex and group (diabetic vs. nondiabetic), with age eligibility criteria and ineligibility where applicable.

\begin{tabular}{|c|c|c|c|}
\hline $\begin{array}{l}\text { Preventive care measure/ } \\
\text { Sex/Group }\end{array}$ & $\begin{array}{l}\text { Age eligibility } \\
\text { criteria }\end{array}$ & Guidelines & Ineligibility \\
\hline \multicolumn{4}{|l|}{ Lipid screening } \\
\hline \multicolumn{4}{|l|}{ Men } \\
\hline Diabetic & $>40$ years & Blood level every 2 years & $N A^{a}$ \\
\hline Nondiabetic & $>40$ years & Blood level every 5 years & NA \\
\hline \multicolumn{4}{|l|}{ Women } \\
\hline Diabetic & $>40$ years & Blood level every 2 years & NA \\
\hline Nondiabetic & $>50$ years & Blood level every 5 years & NA \\
\hline \multicolumn{4}{|l|}{ Glucose screening } \\
\hline \multicolumn{4}{|l|}{ Men \& women } \\
\hline Nondiabetic & $>40$ years & Blood level every 3 years & NA \\
\hline \multicolumn{4}{|l|}{ Cervical cancer screening } \\
\hline Women & 20-69 years & Pap ${ }^{b}$ test every 3 years & $\begin{array}{l}\text { Previous diagnosis of cervical, } \\
\text { ovarian, and endometrial } \\
\text { cancer, or hysterectomy }\end{array}$ \\
\hline \multicolumn{4}{|l|}{ Breast cancer screening } \\
\hline Women & $50-69$ years & Mammography every 2 years & $\begin{array}{l}\text { Previous diagnosis of breast } \\
\text { cancer }\end{array}$ \\
\hline \multicolumn{4}{|l|}{ Colorectal cancer screening } \\
\hline Men \& women & $50-74$ years & $\begin{array}{l}\text { - } \text { FOBTC every } 2 \text { years }_{\text {- }} \text { Sigmoidoscopy, every } 5 \text { years } \\
\text { - Colonoscopy, every } 10 \text { years }\end{array}$ & $\begin{array}{l}\text { Previous diagnosis of } \\
\text { colorectal cancer, or colectomy } \\
\text { or colorectal exclusion }\end{array}$ \\
\hline \multicolumn{4}{|l|}{ Eye exam } \\
\hline \multicolumn{4}{|l|}{ Men \& women } \\
\hline Diabetic & $>40$ years & Two tests every 2 years & NA \\
\hline \multicolumn{4}{|l|}{ Hemoglobin A1c screening } \\
\hline \multicolumn{4}{|l|}{ Men \& women } \\
\hline Diabetic & $>40$ years & Four blood tests every 2 years & NA \\
\hline
\end{tabular}


Standardized difference was used to assess the matching balance between groups (IDD vs. non-IDD, and IDD who were sent the health communication by mail ("mail-out" group) vs. those with IDD who were not sent the information ("no mail-out" group)). The crude and age-adjusted percentage of adults who received a high PCQS or a periodic health exam was plotted to assess the historical trends; all age-adjusted percentages were stratified by sex. To assess the impact of efforts, two-year percentages were averaged and then rate ratios were calculated to determine if there were within-group or between-group differences over time. To reveal the impact of the 2014 population-based health communication intervention, the results were stratified by intervention group (mail-out vs. no mail-out). The binomial distribution was used to calculate the $95 \%$ confidence intervals (CIs).

The study was approved by the Queen's University Health Sciences and Affiliated Hospitals Research Ethics Board, the University of Ottawa's Research Ethics Board, and the Research Ethics Board at Sunnybrook Health Sciences Centre, Toronto, Canada. All analyses were conducted at ICES, which has a special designation under Ontario's Personal Health Information Protection Act allowing it to collect and use data under strict privacy practices.

\section{RESULTS}

The subgroups of adults with IDD ranged in size from 20030 in 2003 to 28080 in 2016 as, year by year, more individuals were added to the subgroup (reached age 40) than were removed (reached age 65 or died). When data are presented, the year given in always the fiscal year (FY). A fiscal year is from 1 April of the year named to 31 March of the subsequent year. For example, FY 2003 is 1 April 2003 to 31 March 2004. As shown in Table 2, in 2009 (the initial cohort creation year), the average age of adults with IDD was 50.1 years and $54.1 \%$ of subgroup members with IDD were men. On average, they had a moderate illness burden (2.1 ADGs) (29). They were more likely to live in low-income neighborhoods and in urban centers (RIO 0-39 is considered urban (30)). With the exception of increasing mean age and slight fluctuations in ADGs over time, the IDD subgroup characteristics remained stable over the observation period. Table 2 also shows that the matching was successful, resulting in no significant differences in IDD and non-IDD subgroups in each year by matching variables. The standardized differences for 2003, 2009, and 2016 are all 0.01 or smaller.

FIGURE 1. Crude percentage of adults aged 40-64 years old with intellectual and developmental disabilities (IDD) and without intellectual and developmental disabilities (non-IDD) receiving a periodic health exam or scoring 0.6 or greater on the Primary Care Quality Score each fiscal year (1 April to 31 March) from 2003 to 2015 in Ontario, Canada

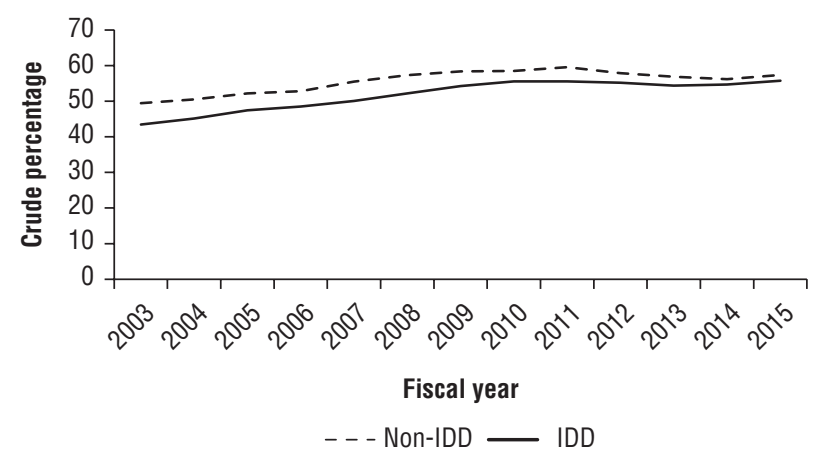

Source: Prepared by the authors, based on the study results.

TABLE 2. Cohort balance across matching variables for adults aged 40 to 64 with intellectual and developmental disabilities (IDD) and without intellectual and developmental disabilities (non-IDD) in fiscal years 2003, 2009, and 2016 in Ontario, Canada

\begin{tabular}{|c|c|c|c|c|c|c|c|c|c|}
\hline \multirow{3}{*}{ Characteristics } & \multicolumn{3}{|c|}{2003} & \multicolumn{3}{|c|}{2009} & \multicolumn{3}{|c|}{2016} \\
\hline & Non-IDD & IDD & \multirow{2}{*}{ St diffa } & Non-IDD & IDD & \multirow{2}{*}{ St diff } & Non-IDD & IDD & \multirow{2}{*}{ St diff } \\
\hline & $N=19961$ & $N=20030$ & & $N=27176$ & $N=27468$ & & $N=27910$ & $N=28080$ & \\
\hline Age (years) $(\text { mean } \pm S D)^{b}$ & $47.39 \pm 5.22$ & $46.36 \pm 5.21$ & 0.01 & $50.13 \pm 6.54$ & $50.11 \pm 6.53$ & $<0.01$ & $51.46 \pm 6.77$ & $51.46 \pm 6.76$ & $<0.01$ \\
\hline \multicolumn{10}{|l|}{ Sex (no. and \%) } \\
\hline Female & $9106(45.6 \%)$ & $9173(45.8 \%)$ & $<0.01$ & $12378(45.5 \%)$ & $12595(45.9 \%)$ & 0.01 & $12641(45.3 \%)$ & $12753(45.4 \%)$ & $<0.01$ \\
\hline Male & $10855(54.4 \%)$ & $10857(54.2 \%)$ & $<0.01$ & $14798(54.5 \%)$ & $14873(54.1 \%)$ & 0.01 & $15269(54.7 \%)$ & $15327(54.6 \%)$ & $<0.01$ \\
\hline $\mathrm{ADGS}^{\mathrm{c}}($ mean $\pm \mathrm{SD})$ & $1.93 \pm 2.84$ & $1.95 \pm 2.81$ & 0.01 & $1.95 \pm 2.75$ & $2.04 \pm 2.87$ & 0.03 & $2.10 \pm 2.96$ & $2.17 \pm 3.07$ & 0.02 \\
\hline \multicolumn{10}{|l|}{ Income quintile (no. and \%) } \\
\hline 1 - lowest & $6849(34.3 \%)$ & $6780(33.8 \%)$ & 0.01 & $9187(33.8 \%)$ & $9131(33.2 \%)$ & 0.01 & $9193(32.9 \%)$ & $9119(32.5 \%)$ & 0.01 \\
\hline 2 & $4460(22.3 \%)$ & $4450(22.2 \%)$ & $<0.01$ & $5978(22.0 \%)$ & $6010(21.9 \%)$ & $<0.01$ & $6058(21.7 \%)$ & $6109(21.8 \%)$ & $<0.01$ \\
\hline 3 & $3353(16.8 \%)$ & $3382(16.9 \%)$ & $<0.01$ & $4605(16.9 \%)$ & $4734(17.2 \%)$ & 0.01 & $4887(17.5 \%)$ & $4893(17.4 \%)$ & $<0.01$ \\
\hline 4 & $2927(14.7 \%)$ & $3002(15.0 \%)$ & 0.01 & $4094(15.1 \%)$ & $4181(15.2 \%)$ & $<0.01$ & $4331(15.5 \%)$ & $4429(15.8 \%)$ & 0.01 \\
\hline 5 - highest & $2372(11.9 \%)$ & $2416(12.1 \%)$ & 0.01 & $3312(12.2 \%)$ & $3412(12.4 \%)$ & 0.01 & $3441(12.3 \%)$ & $3530(12.6 \%)$ & 0.01 \\
\hline Rurality (mean \pm SD) & $15.29 \pm 19.94$ & $15.43 \pm 19.96$ & 0.01 & $14.81 \pm 19.78$ & $14.98 \pm 19.80$ & 0.01 & $14.00 \pm 19.10$ & $14.11 \pm 19.20$ & 0.01 \\
\hline
\end{tabular}

Source: Prepared by the authors, based on the study results.

a St diff = standardized difference

${ }^{\mathrm{b}} \mathrm{SD}=$ standard deviation.

${ }^{\mathrm{c}} \mathrm{ADGs}=$ Aggregated Diagnosis Groups 
Figure 1 depicts the time trend (2003 to 2015) for the composite outcome (PHE or PCQS $\geq 0.6$ ) for IDD and non-IDD subgroups. An increase in the percentage with IDD meeting criteria for the composite outcome was observed over time, from $43.4 \%$ in 2003 to $55.7 \%$ in 2015 . A comparable increase was observed in the non-IDD subgroups but only until 2011. After that, the percentage declined to $57.4 \%$ in 2015 , resulting in a narrowing of the gap between IDD and non-IDD subgroups.

Age-adjusting and stratifying the outcome by sex reveals that the narrowing of the gap due to sustained improvements after 2010 is seen only in men with IDD (Figure 2). Over the 13-year period, after adjusting for age, a $53.7 \%$ increase in the outcome was seen in men with IDD (39.3\% to $60.4 \%)$, compared to only $31.4 \%$ in men without IDD $(41.3 \%$ to $54.3 \%$ ). For the two groups of women, however, after adjusting for age, the percent increases from 2003 to 2015 were more similar $(30.9 \%$ for those with IDD, $23.0 \%$ for those without IDD) (Figure 3). The persisting gap seen in women is due in part to the disparity between the two groups of women with regards to the outcome in 2003 , when only $37.0 \%$ of women with IDD met the criteria for the composite outcome, compared to $47.5 \%$ of women without IDD.

Table 3 provides two-fiscal-year average percentages for the composite outcome stratified by sex for IDD and non-IDD subgroups. According to the time trends analysis, the improvement is only seen in males with IDD. Rate ratios comparing the percentages of all IDD subgroup members in subsequent years who met the criteria for the composite outcome in relation to previous years reveal a gradual modest increase in males (e.g., rate ratio of 1.04 when comparing 2015 and 2016 to 2009 and 2010), but a decline in women (e.g., rate ratio of 0.95 when comparing 2013 and 2014 or 2015 and 2016 to 2009 and 2010) (Table 3).

When examining the difference over time between those who were mailed the health communication intervention in October 2014 (mail-out; n = 13790 in 2003 to $n=19102$ in 2016) and those who were not sent the information (no mailout; $\mathrm{n}=6240$ in 2003 to $\mathrm{n}=8978$ in 2016), the improvement in uptake in males only persists (Table 4). Following the October 2014 intervention, a small but statistically significant increase was observed among men in the mail-out group (rate

FIGURE 2. Age-adjusted percentage of men aged 40-64 years old with intellectual and developmental disabilities (IDD) and without intellectual and developmental disabilities (non-IDD) receiving a periodic health exam or scoring 0.6 or greater on the Primary Care Quality Score each fiscal year (1 April to 31 March) from 2003 to 2015 in Ontario, Canada

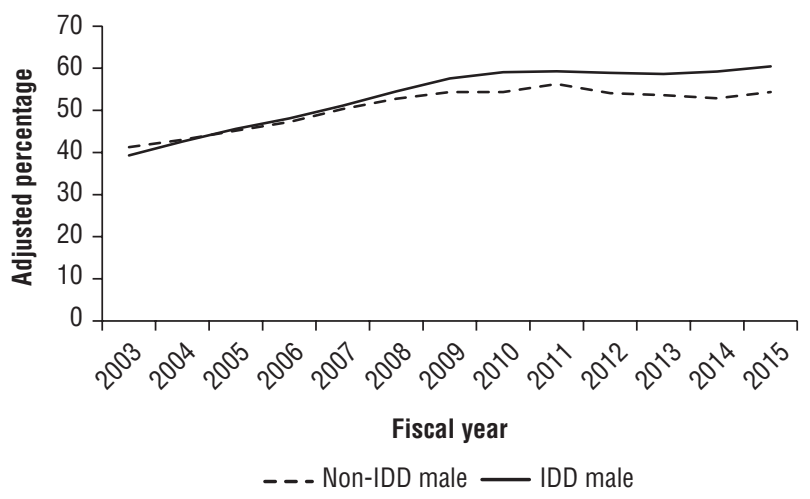

Source: Prepared by the authors, based on the study results.

FIGURE 3. Age-adjusted percentage of women aged 40-64 years old with intellectual and developmental disabilities (IDD) and without intellectual and developmental disabilities (non-IDD) receiving a periodic health exam or scoring 0.6 or greater on the Primary Care Quality Score each fiscal year (1 April to 31 March) from 2003 to 2015 in Ontario, Canada

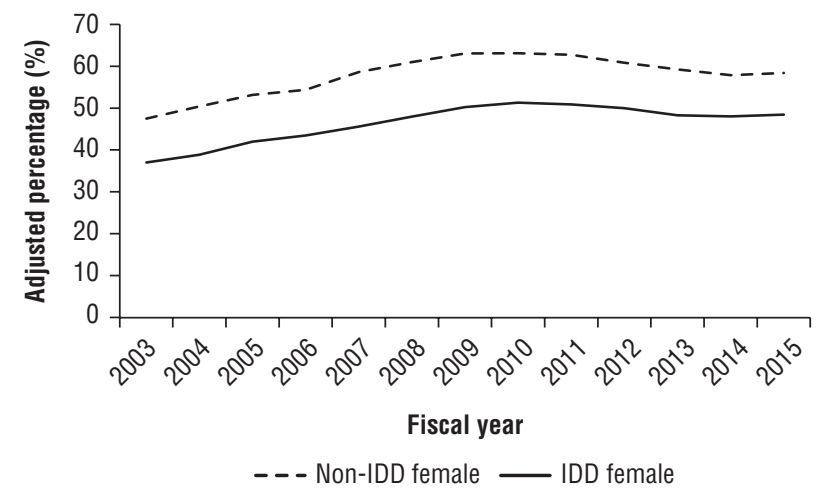

Source: Prepared by the authors, based on the study results.

ratio of 1.03 (95\% CI: 1.01-1.05) when comparing 2015 and 2016 to 2013 and 2014), while no change was seen among women (rate ratio of 1.01. 95\% CI: 0.991.04) when comparing 2015 and 2016 to 2013 and 2014) (Table 4).

In summary, when comparing the twoyear average percentages comparing IDD vs. non-IDD (Table 3) and mail-out vs. no-mail-out groups (Table 4), we see that the publication of guidelines, dissemination of tools, and hiring of health care facilitators in FY 2011 and the October 2014 health communication intervention had a small but statistically significant effect in increasing the percentage of men with IDD receiving a health exam or high PCQS. No effect was seen among women with IDD that could not be attributed to changes in practice regarding preventive care for women generally.

\section{DISCUSSION}

Ontario's approach to improving primary care provision to adults with IDD since 2006 has had a marginal impact on individuals 40 to 64 years of age. The efforts have included disseminating guidelines and tools, designating regional personnel to promote the use of the guidelines, and informing adults with IDD to avail themselves of the periodic health examination. Despite these actions, in 2015, over $44 \%$ of 
TABLE 3. Comparison of two-fiscal-year average percentages of adults aged 40 to 64 years with intellectual and developmental disabilities (IDD) and without intellectual and developmental disabilities (IDD) who received a score of 0.6 or greater on the Primary Care Quality Score (PCQS) and/or a periodic health exam (PHE) from 1 April 2009 to 31 March 2017 in Ontario, Canada, stratified by sex

\begin{tabular}{|c|c|c|c|c|c|}
\hline \multirow{2}{*}{ Sex/Fiscal yeara } & \multicolumn{2}{|c|}{ Average percentage (95\% confidence interval) } & \multicolumn{3}{|c|}{ IDD rate ratio (95\% confidence interval) } \\
\hline & IDD & Non-IDD & vs. $2009 \& 2010$ & vs. $2011 \& 2012$ & Vs. $2013 \& 2014$ \\
\hline \multicolumn{6}{|l|}{ Male } \\
\hline $2009 \& 2010$ & $58.31(57.75-58.87)$ & $54.34(53.78-54.90)$ & $N A^{b}$ & NA & NA \\
\hline $2013 \& 2014$ & $58.93(58.38-59.49)$ & $53.24(52.68-53.80)$ & $1.01(1.00-1.02)$ & $1.00(0.98-1.01)$ & NA \\
\hline $2015 \& 2016$ & $60.42(59.63-61.21)$ & $54.34(53.54-55.14)$ & $1.04(1.02-1.05)$ & $1.02(1.01-1.04)$ & $1.03(1.01-1.04)$ \\
\hline $2011 \& 2012$ & $50.42(49.81-51.03)$ & $61.79(61.20-62.39)$ & $0.99(0.98-1.01)$ & NA & NA \\
\hline $2013 \& 2014$ & $48.14(47.53-48.76)$ & $58.55(57.94-59.16)$ & $0.95(0.93-0.97)$ & $0.95(0.94-0.97)$ & NA \\
\hline $2015 \& 2016$ & $48.45(47.57-49.32)$ & $58.42(57.55-59.28)$ & $0.95(0.93-0.98)$ & $0.96(0.94-0.98)$ & $1.01(0.98-1.03)$ \\
\hline
\end{tabular}

Source: Prepared by the authors, based on the study results.

a 2015 \& 2016 is average of 2015 PCQS or PHE and 2016 PHE due to data required to compute PCQS for 2016 not being available at time of analysis.

${ }^{\mathrm{b}} \mathrm{NA}=$ not applicable.

TABLE 4. Comparison of adults aged 40 to 64 years with intellectual and developmental disabilities two-fiscal-year average percentage of who received and did not receive the mail-out who received a score of 0.6 or greater on the Primary Care Quality Score (PCQS) and/or a periodic health exam (PHE) from 1 April 2009 to 31 March 2017 in Ontario, Canada, stratified by sex

\begin{tabular}{|c|c|c|c|c|c|}
\hline \multirow{2}{*}{ Sex/Fiscal yeara } & \multicolumn{2}{|c|}{ Average percentage ( $95 \%$ confidence interval) } & \multicolumn{3}{|c|}{ Mail-out rate ratio ( $95 \%$ confidence interval) } \\
\hline & Mail-out & No mail-out & vs. $2009 \& 2010$ & vs. 2011 \& 2012 & vs. $2013 \& 2014$ \\
\hline \multicolumn{6}{|l|}{ Male } \\
\hline $2009 \& 2010$ & $57.11(56.45-57.78)$ & $61.03(60.01-62.05)$ & $N A^{b}$ & NA & NA \\
\hline $2013 \& 2014$ & $58.69(58.02-59.35)$ & $59.42(58.38-60.45)$ & $1.03(1.01-1.04)$ & $1.01(0.99-1.02)$ & NA \\
\hline $2015 \& 2016$ & $60.61(59.67-61.55)$ & $59.92(58.45-61.39)$ & $1.06(1.04-1.08)$ & $1.04(1.02-1.06)$ & $1.03(1.01-1.05)$ \\
\hline \multicolumn{6}{|l|}{ Female } \\
\hline $2011 \& 2012$ & $47.31(46.55-48.06)$ & $56.30(55.27-57.34)$ & $0.99(0.97-1.02)$ & NA & NA \\
\hline $2013 \& 2014$ & $45.22(44.46-45.97)$ & $53.72(52.67-54.76)$ & $0.95(0.93-0.97)$ & $0.96(0.93-0.98)$ & NA \\
\hline $2015 \& 2016$ & $45.89(44.81-46.97)$ & $53.30(51.82-54.78)$ & $0.96(0.94-0.99)$ & $0.97(0.94-1.00)$ & $1.01(0.99-1.04)$ \\
\hline
\end{tabular}

Source: Prepared by the authors, based on the study results.

a 2015 \& 2016 is average of 2015 PCQS or PHE and 2016 PHE due to data required to compute PCQS for 2016 not being available at time of analysis.

${ }^{\mathrm{b}} \mathrm{NA}=$ not applicable.

adults with IDD who were 40 to 64 years old did not receive recommended preventive care. For this group, the efforts in Ontario to enhance preventive care have not been as successful as the incentive-based approach tested in England (31).

Our findings suggest that the efforts in Ontario may have small incremental effects, but only for men. A number of factors may have contributed to the lack of significant change in preventive care among women with IDD. One factor relates to the additional challenges inherent to female-specific cancer screening. Such challenges include obtaining valid consent for invasive procedures such as the Pap test, and addressing women's fear, embarrassment, and lack of understanding related to the Pap test and mammography. These barriers may not be limited to female-specific cancer screening. A study of the general population in the United Kingdom showed that women report more fear of discomfort, embarrassment, and anxiety with regard to invasive cancer screening procedures than do men (32). Though approaches have been developed to support women with IDD undergoing cancer screening, they have not been widely adopted (33).

A limitation of our study was our inability to determine how many of the adults with IDD who received the October 2014 health communication intervention (the mail-out group) were unable to access the periodic health examination. A follow-up survey to the mail-out group members revealed challenges with access. Among those who volunteered to participate in the survey (85 adults with IDD and 85 caregivers), some reported that the adult with IDD did not have a family doctor $(6 \%)$, some caregivers did not deem it important for the individual with IDD to have a periodic health exam (9\%), and some reported that the family doctor was not willing to perform the periodic health examination $(2 \%)(34,35)$. Another limitation was our reliance on health administrative data to capture information on preventive care. Such data is limited to 
activities for which physicians can bill the provincial health insurance plan. Important preventive care activities such as weight and blood pressure monitoring, smoking cessation, and dietary advice are not captured in the data sets available at this time.

A strength of this study was the ability to use matching to control for differences between adults with IDD and those without IDD. As such, differences seen in the quality of primary care are unlikely to be attributable to differences in sociodemographic or morbidity differences in the groups. However, it is important to note that the reported percentages for the non-IDD subgroups do not represent the non-IDD population per se but rather the experience of a sample similar to the IDD subgroups in terms of age, sex, neighborhood income, rurality, and morbidity.

Future research should consider other potential outcomes of efforts such as those examined in this study, including improvements to patient awareness and comfort in patient-physician communication. Research is also needed to document and understand the impact of initiatives to improve preventive care to younger and older individuals with IDD. In the absence of recommended and billable activities relevant to these outcomes and age groups, such studies will require different data and study designs.

1. Ouellette-Kuntz H, Garcin N, Lewis S, Minnes P, Freeman C, Holden J. Addressing health disparities through promoting equity for individuals with intellectual disabilities. Can J Public Health. 2005 Mar 1;96(2):S8-S22.

2. Ouellette-Kuntz H. Understanding health disparities and inequities faced by individuals with intellectual disabilities. J Appl Res Intellect Disabil. 2005 May 17;18(2):113-21.

3. International Conference on Primary Health Care. Declaration of Alma-Ata. Available from: http://www.who.int/ publications/almaata_declaration_en.pdf Accessed on 12 December 2017.

4. International Disability Network. International disability rights monitor: regional report of the Americas 2004. Available from: http:/ / bbi.syr.edu/publications/blanck docs/2003-2004/IDRM_Americas_2004.pdf Accessed on 12 December 2017.

5. Office of the Surgeon General; National Institute of Child Health and Human Development; Centers for Disease Control and Prevention. Closing the gap: a national blueprint to improve the health of

\section{Conclusions}

Across the province, Ontario has invested in several interconnected strategies to improve primary care provision to adults with IDD. Continued monitoring of the quality of that care is warranted to better understand the long-term impacts of the initiatives.

According to the results of our study, the dissemination of guidelines and tools to physicians or targeting adults with IDD through a mail-out had little impact on uptake of preventive care at the population level in the short term. Although sex differences have been identified, the barriers to uptake for adults with IDD remain unclear. Moving forward, it will be important to thoroughly explore the barriers to preventive care uptake for adults with IDD. A variety of new approaches to improving such care could be considered, including financial incentives and quality assurance measures targeting primary care providers, advocacy to change funding policies and practices, and continued education and empowerment of adults with IDD and their caregivers. The way forward should be informed by a strong theoretical basis and be supported by a thorough understanding of barriers. It will be important to examine how much value different strategies contribute to measured outcomes and understand how they interact to affect outcomes.

\section{REFERENCES}

persons with mental retardation: report of the Surgeon General's Conference on Health Disparities and Mental Retardation. Available from: https://www.nichd.nih. gov/publications / pubs / closingthegap/ Pages/index.aspx Accessed on 15 December 2017.

6. Rimmer JH, Rowland JL, Yamaki K. Obesity and secondary conditions in adolescents with disabilities: addressing the needs of an underserved population. J Adolesc Health. 2007 Sept 30;41(2):224-9.

7. Frey GC, Temple VA. Health promotion for Latin Americans with intellectual disabilities. Salud Publica Mex. 2008;50 Suppl 2:s167-77.

8. Robertson J, Hatton C, Emerson E, Baines $\mathrm{S}$. The impact of health checks for people with intellectual disabilities: an updated systematic review of evidence. Res Dev Disabil. 2014 Oct 1;35(10):2450-62.

9. Baxter H, Lowe K, Houston H, Jones G, Felce D, Kerr M. Previously unidentified morbidity in patients with intellectual disability. Br J Gen Pract. 2006 Feb 1; 56(523):93-8.
Funding and acknowledgments. This study was supported by a Partnerships in Health Systems Improvement grant (PHE \#103973) from the Canadian Institutes of Health Research (CIHR), using data provided by the Ontario Ministry of Health and Long-Term Care (MOHLTC), the Ontario Ministry of Community and Social Services (MCSS), and the Institute for Clinical Evaluative Sciences (ICES). The opinions, results, and conclusions reported in this article are those of the authors and do not necessarily represent the funding sources and data providers. No endorsement by the CIHR, MOHLTC, MCSS, or ICES is intended or should be inferred. Parts of this material are based on data provided by the Canadian Institute for Health Information (CIHI) and by Cancer Care Ontario (CCO). However, the analyses, conclusions, opinions, and statements expressed herein are those of the authors, and are not necessarily those of $\mathrm{CIHI}$ or CCO. No endorsement by CIHI or $\mathrm{CCO}$ is intended or should be inferred.

\section{Conflicts of interest. None declared.}

Disclaimer. Authors hold sole responsibility for the views expressed in the manuscript, which may not necessarily reflect the opinion or policy of the RPSP/ PAJPH or PAHO.
10. Lennox N, Bain C, Rey-Conde T, Purdie D, Bush R, Pandeya N. Effects of a comprehensive health assessment programme for Australian adults with intellectual disability: a cluster randomized trial. Int J Epidemiol. 2007 Jan 11;36(1):139-46.

11. Lennox N, Ware R, Bain C, Taylor Gomez M, Cooper SA. Effects of health screening for adults with intellectual disability. Br J Gen Pract. 2011 March 1;61(584):193-6.

12. Perry J, Kerr M, Felce D, Bartley S, Tomlinson J. Monitoring the public health impact of health checks for adults with a learning disability in Wales: final report of the Joint Public Health Wales/WCLD Project Group. Available from http:// www.wales.nhs.uk/sites3/Documents / 256/Health_Checks_Final_Report_ March_2010.pdf Accessed on 27 July 2018.

13. Glover G, Niggebrugge A. The uptake of health checks for adults with learning disabilities 2008/9 to 2012/13. London: Public Health England; 2012.

14. Chauhan U, Reeve J, Kontopantelis E, Hinder S, Nelson P, Doran T. Impact of the English directly enhanced service (DES) 
for learning disability. Manchester: The University of Manchester; 2012.

15. Mavriplis CA. Should we abandon the periodic health examination? Can Fam Physician. 2011 Feb 1;57(2):159-61.

16. Krogsboll LT, Jorgensen KJ, Larsen CG, Gotzsche PC. General health checks in adults for reducing morbidity and mortality from disease. Cochrane systematic review and meta-analysis. BMJ. 2012 Nov 20;345:e7191.

17. Lunsky Y, Jaakkimainen L, Sullivan W, Balogh R. Periodic health exams for adults with developmental disabilities: Are we doing enough? Can Fam Physician. 2014 Feb 1;60(2):109-10.

18. Klein-Geltink JE, Yates E Lunsky Y, eds. Atlas on the primary care of adults with developmental disabilities in Ontario. Toronto: Institute for Clinical Evaluative Sciences; 2013.

19. Cobigo V, Ouellette-Kuntz H, Balogh R, Leung F, Lin E, Lunsky Y. Are cervical and breast cancer screening programs equitable? The case of women with developmental disabilities. J Intellect Disabil Res. 2013 March 19;57(7):478-88.

20. Sullivan WF, Heng J, Cameron D, Lunsky Y, Cheetham T, Hennen B, et al. Consensus guidelines for primary health care of adults with developmental disabilities. Can Fam Physician. 2006 Nov 1;52(1):1410-8.

21. Sullivan WF, Berg JM, Bradley E, Cheetham T, Denton R, Heng J, et al. Primary care of adults with developmental disabilities: Canadian consensus guidelines. Can Fam Physician. 2011 May 1; 57(5):541-53.

22. Lennox N, Bain C, Rey-Conde T, Taylor M, Boyle FM, Purdie DM, et al. Cluster randomized controlled trial of interventions to improve health for adults with intellectual disability who live in private dwellings. J Appl Res Intellect Disabil. 2010 July;23(4):202-11.

23. Potvin L, Fulford C, Ouellette-Kuntz H, Cobigo V. What adults with developmental disabilities expect of their family physicians. Can Fam Physician. In press.

24. Lin E, Balogh R, Isaacs B, Ouellette-Kuntz $\mathrm{H}$, Selick A, Wilton AS, et al. Strengths and limitations of health and disability support administrative databases for population-based health research in intellectual and developmental disabilities. J Policy Pract Intellect Disabil. 2014 Jan 23;11(4): 235-44.

25. Kralj B. Measuring rurality - RIO2008 BASIC: methodology and results. Toronto: Ontario Medical Association Economics Department; 2009.

26. Smith G, Ouellette-Kuntz H, Green M. Comprehensive preventive care assessments for adults with intellectual and developmental disabilities. Part 1: How do we know if it's happening? Can Fam Physician. 2018 Apr 1;64(Suppl 2):S57-S62.

27. Dahrouge S, Hogg W, Younger J, Muggah E, Russell G, Glazier RH. Primary care physician panel size and quality of care: a population-based study in Ontario, Canada. Ann Fam Med. 2016 Jan 1;14(1):26-33.

28. Smith G. Uptake of the periodic health exam among adults with intellectual and developmental disabilities from 2003 to 2015 [dissertation]. Kingston, Ontario, Canada: Queen's University; 2016.

29. Manitoba Centre for Health Policy. Term: comorbidity level. Available from: mchpappserv.cpe.umanitoba.ca / viewDefinition.php?definitionID=102448 Accessed 31 October 2017.

30. Tran C, Wijeysundera HC, Qui F, Tu JV, Bathia S. Comparing the ambulatory care and outcomes for rural and urban patients with chronic ischemic heart disease: a population-base cohort study. Circ Cardiovasc Qual Outcomes. 2014 Nov; 7(6):835-43.

31. Buszewicz M, Welch C, Horsfall L, Nazareth D, Osborn D, Hassiotis A, et al. Assessment of an incentivised scheme to provide annual health checks in primary care for adults with intellectual disability: a longitudinal cohort study. Lancet Psychiatry. 2014 Dec 31;1(7):522-30.

32. Wardle J, Miles A, Atkin W. Gender differences in utilization of colorectal cancer screening. J Med Screen. 2005 Mar 1; 12(1):20-7.

33. Parish SL, Rose RA, Luken K, Swaine JG, O'Hare L. Cancer screening knowledge changes: results from a randomized control trial of women with developmental disabilities. Res Soc Work Pract. 2012 Jan 1;22(1):43-53.

34. Ouellette-Kuntz H, Fulford C, Cobigo V, Potvin L. Annual health exam for adults with intellectual and developmental disabilities: the perspective of caregivers. J Intellect Disabil Res. 2016 July 22; 60(7-8):803.

35. Ouellette-Kuntz H, Fulford C, Cobigo V, Potvin L. Importance of and intention to book the annual health exam: the perspective of adults with intellectual and developmental disabilities. J Intellect Disabil Res. 2016 July 22;60(7-8):804.

Manuscript received on 29 December 2017. Revised version accepted for publication on 2 August 2018 
RESUMEN

\section{¿Estamos logrando un cambio en la atención primaria a adultos con discapacidades intelectuales y del desarrollo?}

Palabras clave
Objetivos. Examinar el impacto de la diseminación de guías para médicos y de una intervención de comunicación de salud para la población sobre el porcentaje de adultos con discapacidades intelectuales y del desarrollo (DID) que reciben asistencia preventiva a través de la atención primaria.

Métodos. Se compararon adultos de 40 a 64 años con DID no institucionalizados de la provincia de Ontario, Canadá, con habitantes de Ontario sin discapacidad en cada año fiscal (AF) desde 2003 hasta 2016. Se utilizaron datos administrativos de salud para crear una medida compuesta indicadora de haber recibido la atención primaria preventiva recomendada. Se usaron tasas ajustadas por edad para evaluar las tendencias y los índices de frecuencia (RR) e intervalos de confianza (IC) promedio de dos años para evaluar la efectividad de las intervenciones.

Resultados. El número de adultos con DID identificados varió de 20030 en el AF 2003 a 28080 en el AF 2016. El porcentaje de adultos con DID que recibieron la atención primaria preventiva recomendada varió del 43,4\% en 2003 al 55,7\% en 2015. Los varones con DID presentaron un aumento del 53,7\% a lo largo de los 13 años, mientras que las mujeres con DID solo tuvieron un aumento del 30,9\%. Al evaluar el impacto de las intervenciones, los varones con DID mostraron un $4 \%$ más de probabilidades (RR: 1,04; IC 95\%: 1,02-1,05) de recibir la atención primaria recomendada en los AF 2015 y 2016 en comparación con los AF 2009 y 2010; en comparación, las mujeres con DID presentaron un 5\% menos de probabilidad (RR: 0,95; IC 95\%: 0,93-0,98). Se observó una disminución comparable entre las mujeres sin DID.

Conclusiones. Aproximadamente el $45 \%$ de los adultos con DID en Ontario aún no reciben la atención preventiva recomendada a través de la atención primaria. Los impactos a largo plazo de las intervenciones introducidas en la provincia aún pueden ocurrir a lo largo del tiempo, por lo que se requiere un monitoreo continuo. Se debe prestar especial atención a las necesidades de atención preventiva de las mujeres con DID.

Servicios preventivos de salud; discapacidad intelectual; atención primaria de salud; Canadá. 
RESUMO

Estamos conseguindo uma mudança na atenção primária para adultos com deficiências intelectuais e de desenvolvimento?

Palavras-chave
Objetivos. Examinar o impacto da disseminação de diretrizes para médicos é da intervenção de comunicação em saúde em nível populacional sobre a porcentagem de adultos com deficiência intelectual e de desenvolvimento (DID) que recebem cuidados preventivos por meio de atenção primária.

Métodos. Adultos não institucionalizados com DID na província de Ontário, Canadá, com idades entre 40 e 64 anos foram comparados com os habitantes de Ontário sem deficiência, em cada exercício fiscal (AF) desde 2003 a 2016. Dados de saúde administrativos foram usados para criar uma medida de ter recebeu cuidados preventivos recomendados. As taxas ajustadas por idade foram usadas para avaliar as tendências, e as razões de frequência (RR) e os intervalos de confiança média (IC) de dois anos foram utilizados para avaliar a eficácia das intervenções.

Resultados. O número de adultos com DID identificados variou de 20030 no AF 2003 para 28080 no AF 2016. A percentagem de adultos com DID que recebeu cuidados preventivos recomendados variou de 43,4\% em 2003 para 55,7\% em 2015. Homens com DID mostraram um aumento de 53,7\% ao longo dos 13 anos, enquanto as mulheres com DID só apresentaram aumento de 30,9\%. Ao avaliar o impacto das intervenções, os homens com DID mostraram uma probabilidade 4\% maior (RR: 1,04, IC 95\%: $1,02-1,05)$ de receber cuidados primarios recomendados em os AF 2015 e 2016 em comparação com os AF 2009 e 2010; em contraste, as mulheres com DID tiveram uma probabilidade 5\% menor (RR: 0,95, IC 95\%: 0,93-0,98). Uma diminuição comparável foi observada entre as mulheres sem DID.

Conclusões. Aproximadamente $45 \%$ dos adultos com DID em Ontário ainda não recebem cuidados preventivos recomendados através da atenção primária. Os impactos a longo prazo das intervenções introduzidas na província podem ainda ocorrer ao longo do tempo, pelo que é necessária uma monitorização contínua. Atenção especial deve ser dada às necessidades de cuidados preventivos das mulheres com DID.

Serviços preventivos de saúde; deficiência intelectual; atenção primária à saúde; Canadá. 